\title{
SUPERVISÃO DE CAMPO NO SERVIÇO SOCIAL: LOCUS DE FORMAÇÃO E DE RESSINGULARIZAÇÃO DE SABERES
}

Edna Maria Goulart Joazeiro ${ }^{1}$

\section{RESUMO}

$\mathrm{O}$ artigo discute o encontro entre experiência e conhecimento que se realiza na atividade de trabalho da supervisora de campo do e no estágio supervisionado em Serviço Social no Hospital de Ensino Público. Buscou-se compreender e explicitar o caráter interdependente e indissociável dos saberes presentes diuturnamente no trabalho da supervisora, saberes estes que se materializam no diálogo tecido em presença do corpus de saberes da profissão e dos saberes diversos oriundos de outros campos de conhecimento (Pólo 1), dos saberes da disciplina ergológica, presentes no encontro com a população usuária, com o risco de vida e o trabalho (Pólo 2), estando estes pólos em presença e em tensão com os valores mercantis, os valores do bem comum e da vida (Pólo 3) que marcam de modo inelutável esse meio de trabalho e formação. Utilizando as categorias e as ferramentas conceituais da abordagem ergológica, - corpo-si, dramáticas do uso de si, ingredientes da competência humana industriosa, Entidade Coletiva Relativamente Pertinente (ECRP) - intentando-se explicitar que essa atividade de trabalho do e no estágio é no mesmo ato, uso de si por si e uso de si por outrem (SCHWARTZ, 2000), marcando-se ainda a necessidade de colocar em discussão a concepção vigente do estágio como "campo de treinamento" por julgá-la herdeira de outra lógica, a do trabalho como execução.

PALAVRAS-CHAVES: Abordagem ergológica, Supervisão de Campo, Serviço Social, Saúde Pública.

\footnotetext{
${ }^{1}$ Docente da Faculdade de Serviço Social da Pontifícia Universidade Católica de Campinas, assistente social e socióloga, Mestre e Doutora em Educação, membro do Grupo de Pesquisa Geracionalidade, Imaginário e Violência (GEVIM), Supervisora Titular do Programa de Aprimoramento Profissional da FCM/ HC/ UNICAMP/ FUNDAP Serviço Social, Saúde e Violência. E-mail: emgoulart@ uol.com.br.

Revista Serviço Social \& Saúde. UNICAMP Campinas, v. VII-VIII, n. 7-8, Dez. 2009
} 


\section{INTRODUÇÃO}

$\mathrm{O}$ artigo apresenta a análise empreendida a partir da pesquisa de doutorado ${ }^{2}$ que teve como objeto de estudo o encontro entre experiência e conhecimento que se realiza na atividade de trabalho do supervisor de campo de estudantes-estagiários do e no estágio supervisionado em Serviço Social no Hospital de Ensino Público (JoAZEIro, 2008). Intentamos analisar a atividade concreta de supervisionar estudantes-estagiários e buscar compreender a relação e, aí, a articulação entre os saberes disciplinares da profissão, os da saúde e os saberes gerados na atividade de supervisão de campo. Empreendemos um recorte com vistas a introduzir a análise da natureza dos saberes presentes no espaço da supervisão de estágio no Serviço Social na Saúde. Essa questão tem um alcance fundamental à medida que nos permite buscar compreender o lugar que o supervisor de campo ocupa na assistência e na formação.

No Brasil o assistente social é um profissional liberal, de nível superior, cuja formação tem natureza técnico-científica sendo uma profissão de caráter iminentemente interventivo. A primeira lei de regulamentação da profissão instituída em 1957 e as legislações que a sucederam mantiveram o estatuto de obrigatoriedade da realização do curso de graduação em Serviço Social ${ }^{3}$, do estágio supervisionado realizado concomitante ao curso e do trabalho de conclusão de curso, características essas que se constituíram em uma marca no decorrer da história da profissão no Brasil. O curso de graduação em Serviço Social desde a fundação da sua primeira escola no Brasil, na década de trinta, instituiu o estágio como norma acadêmica antecedente obrigatória para

\footnotetext{
${ }^{2}$ Projeto de pesquisa "Supervisão de estágio acadêmico em Serviço Social: formação, temporalidade e produção de saberes", aprovado pelo Comitê de Ética em Pesquisa da FCM/UNICAMP e homologado na IV Reunião Ordinária do CEP/FCM em 17/06/2003. Tese publicada sob o título: Supervisão de Estágio: Formação, Saberes, Temporalidades. Santo André, SP: ESETec, 2008.

${ }^{3}$ BRASIL, Lei n ${ }^{\circ} 3252,27$ de agosto de 1957 e Lei no ${ }^{\circ}$. 8.662, de 7 de junho de 1993, ambas dispõem sobre a profissão de Assistente Social e dá outras providências, no artigo $2^{\circ}$, item I.
} 
a obtenção do diploma de graduação. O estágio se configura a partir da "inserção do aluno no espaço sócio-institucional objetivando capacitá-lo para o exercício do trabalho profissional, o que pressupõe supervisão sistemática" (ABESS/CEDEPSS, p. 71). A prática do estágio está vinculada às disciplinas de Estágio Supervisionado, que se realizam a partir do quinto período do curso de Serviço Social.

O exercício da supervisão de estágio na profissão é uma prerrogativa profissional do assistente social, sendo seu exercício uma atribuição privativa desses profissionais. Na vida profissional do conjunto dos assistentes sociais no país, o exercício da supervisão constitui uma prerrogativa, e não uma exigência com força de lei. A supervisão é essa "prerrogativa” possível e imprescindível à formação.

Um minucioso estudo da produção acadêmica sobre a atividade de supervisionar estudantes-estagiários no Serviço Social revela que existe a tendência a apresentá-la com base em um conteúdo mais normativo que discute o "dever ser" dessa atividade, e pouco tem sido analisado e escrito sobre a realização da atividade concreta de supervisão, os saberes que utiliza e constrói e a temporalidade presente na efetivação dessa atividade de trabalho e vida. A despeito do fato de a supervisão de campo no Serviço Social ser uma atividade que está presente desde as raízes da instituição da profissão, nossa própria experiência na realização dessa atividade em hospital de ensino público, mostrou-nos a opacidade que envolve essa atividade no interior da profissão. Essa quase "invisibilidade" quanto ao seu valor decorre da dificuldade de compreender a articulação entre o mundo do trabalho e o da educação, que tem lugar nesse espaço de trabalho e de formação.

Nossa atividade de trabalho como supervisora de campo de estágio de estudantes bolsistas no Serviço Social do Núcleo das Enfermarias do Hospital das Clínicas da UNICAMP - atividade que realizamos no decorrer de dez anos - levou-nos a indagar 
sobre como se dá a articulação entre o mundo do trabalho e o da educação num meio que se desenvolve sob a premência da realização de atividades numa temporalidade marcada - pela presença e pela tensão - dos valores do bem comum e dos valores mercantis, que têm lugar nesse cotidiano de trabalho e formação.

A pesquisa teve como objeto a atividade de trabalho da supervisora de estágio de Serviço Social em hospital de ensino público. Os sujeitos da pesquisa foram supervisores de estágio que supervisionaram estudantes-estagiários de Serviço Social nas quatro áreas do Hospital de Clínicas da UNICAMP, no período de 1994 a 2003. Os depoimentos dos supervisores ${ }^{4}$ se constituíram em fonte empírica principal e o diário de supervisão da pesquisadora em fonte de informação específica. Privilegiou-se a palavra pela qual os depoimentos são tornados testemunhos e o aporte teórico da ergologia para analisar essa atividade de trabalho o uso de si por si mesmo e a relação e a articulação entre os saberes disciplinares da profissão, da saúde e os gerados na atividade de trabalho no estágio. Essas relação e articulação foram aprendidas nesse meio específico - de cuidado à saúde e de formação - onde estão, em tensão, diversas temporalidades e valores.

A atividade de trabalho do supervisor de estágio foi analisada, inspirada em Schwartz, tomando como referência o "ofício" (SCHWARTZ, 2000, p. 7-68) do assistente social supervisor, constituindo-o "um meio de acesso, talvez privilegiado, mas não exclusivo a este horizonte muito mais genérico" (ibid, p. 60-1), a da sua atividade de trabalho. O ofício aqui é entendido como o fazer da atividade humana industriosa no encontro entre experiência e conhecimentos vários requeridos: os da profissão, os da formação, os do social e os que se criam no aqui e agora, e na

\footnotetext{
${ }^{4}$ A despeito do fato de que em nossa pesquisa todas as supervisoras eram mulheres, no decorrer deste texto, utilizaremos o masculino para aludir à presença de ambos os sexos na atividade concreta de trabalho da Supervisão de Campo no Serviço Social. 
realização da atividade de trabalho. Vale dizer, é ele tanto a invisibilidade ou as antecipações que se "figura[m] na mente" e que se exteriorizam graças às microescolhas, decisões, que o supervisor realiza naquele encontro, de modo diuturno. Desse modo, o ofício transcende o que se denomina comumente por ofício, engloba e remete ao tempo imemorial da história da humanidade devido àquela construção da relação. $\mathrm{Na}$ atividade de supervisão de estágio dá-se o encontro entre os saberes nascidos $\boldsymbol{d} \boldsymbol{a}$ e $\boldsymbol{n} \boldsymbol{a}$ experiência, os saberes disciplinares do âmbito da profissão e os saberes diversos presentes nesse locus de formação e cuidado.

\section{SUPERVISÃO DE CAMPO NO SERVIÇO SOCIAL: DAS RAÍZES À ATUALIDADE}

Nossa experiência no exercício da supervisão de campo levou-nos a buscar compreender o lugar que a supervisão ocupou e ocupa na história da profissão, atividade esta que surgiu na última década do século XIX. A supervisão, enquanto atividade concreta do e no Serviço Social, surgiu antes mesmo da instituição da profissão e de a formação ser instituída, em 1899, nos Estados Unidos. Barrera (1997, p. 20) afirma que a atividade de supervisão no Serviço Social seguiu a mesma trajetória que o trabalho social propriamente dito, situa o início da supervisão profissional no trabalho social de casos realizado no século XIX pela Charity Organization Society (COS).

Nos Estados Unidos, em 1911, o Departamento de Obras Sociais da Fundação Russel Sage, ainda chefiado por Mary Richmond, realizou o primeiro curso de supervisão. Aponta Vieira (1974, p. 38) que um dos primeiros textos existentes sobre Supervisão no Serviço Social foi o de Virgínia Robinson (1936) o qual foi utilizado também no Brasil para introduzir a discussão sobre supervisão. A autora conceituava a supervisão como "processo educacional pelo qual uma pessoa possuidora de conhecimento e experiência prática toma a responsabilidade de treinar outra possuidora 
de menos recursos técnicos" (1936, destaques nossos). A supervisão no âmbito do Serviço Social tem sido sempre analisada como treinamento desde os primórdios de sua instituição na profissão, a compreensão dessa atividade deu-se sobre a égide da definição do trabalho como execução.

O estágio em Serviço Social tem sido considerado, predominantemente, como “treinamento profissional” (BURIOLLA, 1999, p. 17) o que remete à consideração do trabalho como execução e não como uso de si por outro(s) e, no mesmo ato, uso de si por si mesmo. Nessa situação, o trabalho real é pensado como sendo realizado pelo trabalhador - no caso, o supervisor de campo - da maneira como ele é prescrito na norma, pelo conceito. Sob esse ponto de vista desconsidera-se que "a atividade de trabalho só é parcialmente antecipada" (DURAFFOURG, 1998, p. 126). Essa leitura do trabalho como execução da norma antecedente prescrita acarreta sérias dificuldades para compreender o sentido do trabalho e da presença do "sujeito" que o realiza. Essa visão do estágio como "campo de treinamento" tem conseqüências importantes sobre a leitura que se faz da atividade de estágio. Sob essa perspectiva, a experiência no estágio é entendida como "atrelada unilateralmente para o agir, descartando a formação para o pensar, o refletir, o inovar e o recriar" (BURIOLLA, 1999, p. 42).

Rosa afirma que nos estudos do trabalho no Brasil, nos últimos trinta anos, tem sido constante a busca de realização da modelação do trabalho na tentativa de “neutralizar o irredutível, o imprescritível, o não-regulável da atividade humana na atividade do trabalho" (2004, p. 50). Na tentativa de interditar a presença do ser vivo humano, os modelos conceituais retiram do trabalho seu caráter de atividade humana marcada pela história de um ser que faz uso da atividade de linguagem, atividade esta que é o "testemunho do uso de si do trabalhador [...] atestando ser o trabalho sempre o encontro da experiência e conhecimento" (IDEM, 2000, p. 53-4). Rosa (ibid, p. 190) 
assinala que a visão de atividade de trabalho sob a égide da concepção do trabalho como execução dá-se "ancorada na dimensão de média da norma" o que torna o trabalho ““objeto’ racionalizável, circunscrito, delimitado” fazendo com que este permaneça na penumbra, revestindo-se de uma opacidade que não permite vislumbrar os ajustes, as gestões, os saberes que portam os protagonistas da atividade e os que nela são construídos, bem como o compromisso com a educação e formação nela presente. Segundo a autora, a norma fica submetida à noção de média, "sobressaindo o seu papel de sanção homogeneizadora ou de padronização, quer dos homens quer dos acontecimentos, negando-se 'a prioridade ao tempo criador da norma"” (ibid, p. 126).

Esse olhar "homogeneizador" sobre as normas faz com que se apreenda da atividade somente parte de sua complexidade, aquela ínfima que é tornada visível ou manifesta os gestos, as palavras, as decisões tomadas diante de uma dada situação concreta. Passa-se ao largo da trama que impõe a cada um, ao "sujeito", microgestões no aqui e agora, das quais intervenções são necessárias nesses atos não antecipáveis pela norma. No entanto, o "sujeito" as antecipa - as "figura na mente" - e exterioriza essa antecipação no encontro entre sua experiência e os conhecimentos prévios que se constroem nessa trama no ensino, no estágio e no aqui e agora da situação de trabalho. Na intervenção no social, dá-se uma ação com um "sujeito" singular que está situado e se situa no tempo que "faz história" (SCHWARTZ, 2005, p. 234). O que implica que participar dessa trama remete a outra exigência, a de participar deste tempo, de integrálo, e fazê-lo através de intervenções pertinentes.

\section{ERGOLOGIA: UM OUTRO CAMINHO PARA PENSAR O TRABALHO}

Buscamos outro caminho com vista a compreender o lugar que a experiência do e no estágio supervisionado ocupa no processo de formação do assistente social. 
Discordamos que o estágio supervisionado seja reduzido a um lugar de treinamento e que a atividade de trabalho real da supervisora de campo em que nele atua, possa ser considerada como atividade de "treinamento". Entendemos que em decorrência dessa visão, a atividade de trabalho da supervisora tem sido subdimensionada sendo vista como uma atividade centrada "muitas vezes somente no cumprimento das tarefas prático-administrativas, afetas à rotina cotidiana da instituição" (BURIOLLA, 1999, p. 42).

A escolha de utilizar a abordagem ergológica deu-se em função da natureza do objeto estudado e da íntima relação entre a formação e a assistência que se dá nessa atividade de trabalho. Buscou-se analisar a atividade de supervisão como "lugar de um problema, de uma tensão problemática, de um espaço de possíveis sempre a se negociar" (SCHWARTZ, 2000, p. 41). A atividade de trabalho do e no estágio tem sido por nós analisada sob a perspectiva da Ergologia, por entendermos que a atividade de trabalho realizada neste espaço requer do "sujeito" que a realiza fazer uso de si por si mesmo e no mesmo ato está presente o uso de si por outrem (SCHWARTZ, 2002, p. 489). Como afirma Rosa, "os seres humanos não vivem na pura heteronomia. Eles, em sua atividade, sempre retomam a norma, que por sua vez, finca-se em normas passadas, as quais já sofreram retrabalho de ressingularização ou de renormalização de outros seres" (2000, p. 132).

Intentou-se empreender uma aproximação da atividade do supervisor de campo que se revelasse capaz de compreendê-la na sua magnitude, sem perder de vista suas especificidades. Análises mutilantes que identificam a atividade real como se ela se desse, tal qual a norma antecedente ou do trabalho como execução, não nos permitiriam superar a concepção freqüente no campo do Serviço Social que retoma a separação 
teoria e prática ao proceder a uma análise da atividade concreta do trabalho da supervisão do e no Serviço Social.

Nessa escolha está presente o entendimento de que o trabalho é um lugar de debates de normas, valores (SCHWARTZ, 1998, p. 122-23) e de constante apelo a um “sujeito" singular para a realização de escolhas, micro-decisões e gestões de situações realizadas em presença de um novo meio: o hospital de ensino público. Esse meio é saturado de normas e de diversos saberes, especialmente marcado pelas difíceis e contínuas arestas na experiência de viver uma relação de heterodeterminação com o poder e o saber médico.

A Ergologia, segundo Schwartz, evoca um espaço conceitual "entre o trabalho, a atividade, a vida [...] nas continuidades e nas distinções que os amarram e os opõe" porque a atividade é uma matriz permanente de convocação ao saber e, simultaneamente, de desconforto intelectual que se dá numa relação direta com essa característica da atividade humana de "requerer o conceito para compreender-se ela própria como potencial contínuo de [re]configuração do mundo humano e de seus saberes; então, apreende-se melhor uma dimensão profundamente socrática do qual é o paradigma [ergológico], o sentimento de insuficiência do seu próprio saber" (SCHWARTZ, 2000, 61).

Salienta-se que ergológico "é o termo mais neutro, mais extensivo, mais indeterminado para evocar, neste sentido, a atividade humana” (Ibid, p. 683); está ligado à noção de saúde em Canguilhem que o define como arbitragem entre as normas de vida, e que, nesse debate com o meio, convoca todos os horizontes de existência. Os conceitos de meio, saúde e doença, de Canguilhem foram utilizados por entendermos que um olhar sob esta perspectiva nos permite pensar a relação dinâmica e complexa que é tecida entre a formação e a assistência que se realiza nesse meio marcado pela 
presença continuada do que denominamos "objeto" vida/morte (JOAZEIRO, 2008, p. 160).

Os conceitos corpo-si e dramáticas de uso de si foram criados por Schwartz (2000, p. 34 et seq.), para demonstrar as singularidades no uso de si por si e no uso de si por outrem. Estão presentes em toda situação de trabalho, uma vez que nelas estão sempre presentes as infidelidades do meio (CANGUILHEM, 1995, p. 159). Schwartz afirma que não há situação de trabalho “que não convoque as 'dramáticas de uso de si', as quais se prendem aos horizontes de uso dos quais cada um avalia a trajetória e o produto ao mesmo tempo individual, social, do que é levado a fazer" (SCHWARTZ, 1998, p. 107). Na perspectiva da abordagem ergológica tem-se os pólos 1 e 2. No pólo 1 estão relacionados os saberes disciplinares que não podem, de forma alguma, serem anulados. Esse pólo é sempre acompanhado de uma incultura, relativa a tudo que a atividade recria de saberes, de valores, de histórias particulares de que os trabalhadores são portadores (SCHWARTZ, 2001, p. 12). No pólo 2 situam-se os saberes constituídos a partir do que o autor denomina forças de convocação e de reconvocação - que são os saberes gerados nas atividades que se constituem saberes específicos que transformam continuamente a situação concreta de trabalho. Esses saberes estão ancorados nas histórias e situações concretas $\boldsymbol{d o}$ e no trabalho e na vida. Na perspectiva da abordagem ergológica o encontro dos pólos 1 e 2 dá-se, necessariamente, em presença de um terceiro pólo, que está ligado aos valores, à medida que se articula sobre uma filosofia da humanidade pautada numa maneira de ver o outro e a si mesmo.

A atividade humana industriosa devido ao seu caráter híbrido, requer, para sua realização um espectro de ingredientes que não podem ser descritos e avaliados ou mensurados com base na norma ou em uma grade homogênea. Sua ascese requer ingredientes de natureza diferenciados para compreender suas especificidades. Schwartz 
propôs o uso de seis ingredientes da competência humana industriosa ${ }^{5}$ como alternativa de análise que se opõe à difundida forma de compartimentar a competência em três níveis: "saber, saber-fazer, saber-ser", conhecidas como a "lógica da competência" 6.

\section{HOSPITAL DE ENSINO PÚBLICO: UM ECRP QUE DESAFIA A ASSISTÊNCIA, A FORMAÇÃO E O TRABALHO COLETIVO SINÉRGICO}

Analisamos o hospital de ensino como uma Entidade Coletiva Relativamente Pertinente (ECRP) por entender que como entidade coletiva ele está sempre se fazendo e jamais é tido a priori. O uso deste conceito da Ergologia nos permite buscar compreender o caráter multifacético do meio hospitalar, bem como demarca a presença de múltiplos saberes em movimento que se desenvolvem neste meio marcado pelo uso de ferramentas tecnológicas e por intensas relações de saber e poder. É um lugar de produção de saber e de cuidado. No seu espaço também se ensina, "se trabalham e se transmitem, pelas mais diversas vias: gestuais, ligadas à linguagem, codificadas, o resultado provisório dessas experiências, dessas dramáticas, desses debates de normas" (SCHWARTZ, 2005, p. 242). Nele estão presentes, ainda, múltiplas dimensões relativamente pertinentes ao meio de trabalho que se estabelecem mediante múltiplas relações com as dinâmicas locais, regionais, relacionais, de patrimônio de saberes e de histórias, de uso de técnicas e de relações de poder. Seu coletivo não se limita aos contornos do hospital, ele os ultrapassa uma vez que para cuidar do bem que lhe é confiado - a vida dos outros - ele é remetido sempre na direção de tecer elos com

\footnotetext{
5 Ao falar de competência humana industriosa nos situamos no campo do percurso ergológico, distanciamo-nos radicalmente da denominada lógica da competência, ancorada na definição da formação como 'saber, saber-fazer e saber-ser' emanada da psicologia francesa dos anos 70.

${ }^{6}$ Afirma Maggi que dentro desta perspectiva, o 'saber' é concebido como informação e transmissão de conhecimentos, 'saber-fazer' como aprendizagem de operações e prática de comportamento, 'saber-ser' como integração de condutas, de motivações e tomada de consciência”. MAGGI, Bruno, Les conceptions de la formation et de l'éducation. In: MAGgI, B. (Org.), Manières de penser, manières d'agir en éducation et en formation, p. 2.
} 
outros serviços na defesa da vida, guiando-se nas dinâmicas das histórias locais, instaurando uma dialética de transmissão de "heranças, de ajuda mútua" (SCHWARTZ, 1988, pp. 477-487) que incide sobre a atividade profissional e sobre o exercício da competência humana industriosa nesse meio de trabalho e de formação. Schwartz afirma que num meio marcado pela diversidade de situações e por uma imensa variabilidade de terapêuticas e de saberes em movimento, o quadro relacional pode apagar, ou, pelo contrário, fazer desabrochar competências humanas industriosas.

Nesse espaço de cuidado com a vida, onde as ações, os insumos e as tecnologias utilizadas, são financiados pela racionalidade da temporalidade mercantil, ancorados no tempo do relógio, mas a assistência à vida se dá ancorada numa outra temporalidade, a do vital. Nesse meio, escolhas, decisões e gestões são realizadas ancoradas no itinerário de saberes amealhados pelo trabalhador no decorrer do itinerário de vida marcado tanto pela experiência de um sujeito singular, - nesse estudo, o supervisor de campo de estudantes-estagiários - quanto na experiência coletiva, portanto, historicamente situada. Como Rosa, defendemos que o trabalho é um espaço no qual ocorre “convocação e demanda feitas ao ser vivo humano, e este ser faz uso de si por si mesmo, porque esse lugar - o trabalho - é o permanente debates/confrontos de valores de normas" (ROSA, 2000, p. 52).

Um olhar atendo ao trabalho das diversas profissões na área da saúde nos permite apreender que o cuidado permanece ancorado sobre aspectos vitais. Nele estão presentes variáveis que se relacionam diretamente com o que Canguilhem denomina “como ponto de partida, a noção de ser individual" (1995, p. 148, destaques do autor) e, visto sob essa perspectiva, o "sujeito" que vive a doença no seu corpo terá sempre graus variados de condição de "responder a terapêutica", apreende-se a presença da temporalidade do vital nesse ECRP. A temporalidade do cuidado com a vida nas 
profissões que têm na Biologia, na Fisiologia e na terapêutica, volta-se às questões particulares na relação com o doente, no risco de vida e na terapêutica a ser proposta e a ser seguida. A norma antecedente que financia os tratamentos na área da saúde fixa rigidamente o que vem a ser "o conceito de tempo ideal" para a terapêutica e o cuidado. O tempo, que na norma fica subentendido como um quantum homogêneo, na vida concreta, na atividade real de trabalho pode ser desdobrado em, pelo menos, três dimensões presentes neste ECRP: a do hospital de ensino, a do relógio, a do tempo prescrito para cada procedimento. Essa dimensão aponta para a presença da tensão entre diferentes temporalidades nesse meio: a do corpo em relação ao seu cuidado, a da terapêutica, a do cuidado com a saúde e a mercantil. A temporalidade do financiamento, a mercantil, tende a subsumir as outras temporalidades, subdimensionando-as sob o crivo da gestão dos custos. Essas temporalidades se relacionam com outra norma, a que prescreve o tempo de trabalho definido sob a forma de jornada e de seu dimensionamento linear, ancorado num contínuo do movimento dos ponteiros do relógio a definir o tempo de trabalho. Há a tensão entre a lógica desse contínuo inflexível - o tempo de trabalho - e o fenômeno da "demanda" que se subordina a outra lógica, a da necessidade de cuidados à saúde, marcada pelos limites do corpo, e de sua relação com o adoecer e com a propensão a morrer.

\section{SUPERVISÃO DE CAMPO NO ESTÁGIO: SABERES TEMATIZÁVEIS E NÃO-TEMATIZÁVEIS}

A atividade de trabalho de supervisão de estudantes-estagiários no Serviço Social no campo da saúde se expressa através de uma difícil demanda posta ao supervisor: a de fazer parte do processo de assistência à saúde do doente - porém de um modo diferenciado -, pois sua intervenção lhe impõe apresentar outras perspectivas de 
entendimento do problema do doente e requer vislumbrar possibilidades de intervenção. Espera-se do supervisor que evite fazer uso do direito de agir no lugar do estudanteestagiário. Requer, antes de tudo, um respeito ao processo de formação e de crescimento profissional de outrem: o estudante em formação.

Nessa atividade está presente o desafio de enfrentar a escassez de recursos, a convivência com as equipes de diversas formações e ocupações na realização do trabalho, vivendo diariamente a necessidade de participar de relações de trabalho coletivo e de estabelecer relações sinérgicas num ambiente marcado pela presença da doença, da dor e da morte. Nesse contexto de heterodeterminação intentamos mostrar o uso de si por si, os compromissos que se estabelecem nessa relação e a gestão de situação indispensável no cuidado que tem no horizonte a defesa da vida, da cidadania e a formação do estudante-estagiário. As atividades de trabalho no estágio consistem em momentos de encontro dos estudantes-estagiários com as situações concretas de trabalho e de vida, o que lhes demanda, ao mesmo tempo, a realização tanto da formação quanto da assistência ao doente e aos seus familiares.

$\mathrm{Na}$ atividade de estágio dá-se o encontro entre os saberes nascidos da e na experiência, os saberes disciplinares do âmbito da profissão e os saberes diversos presentes nesse locus de formação e de cuidado. Esse exercício cotidiano requer do supervisor de campo saber "decifrar" o momento oportuno, uma vez que se defronta sempre com "bifurcações" que exigem, do protagonista da atividade, fazer um [re]tratamento da norma antecedente, que se constitui em verdadeiros desafios para os quais não dispõe de "escala absoluta" para guiá-lo. Nessa perspectiva, como afirma Freire, é preciso "saber que ensinar não é transferir conhecimento, mas criar as possibilidades para a sua própria produção ou a sua construção" (FREIRE, 1999, p. 52). Afirma Schwartz (2005) que quando "o ato de transmitir humano no ensino se torna, 
por ambivalentes razões, enfraquecido enquanto cadinho de debates sobre o governo de nossas vidas, o agir, ou seja, a atividade humana de transmitir se torna um continente em penumbra e perde sua formidável potência de interrogação” (ibid., p. 236).

A indissociabilidade dos saberes disciplinares e ergológicos na atividade humana industriosa - a atividade humana e atividade de trabalho - é o cerne da questão que conduz à obrigatoriedade da experiência de campo nas profissões interventivas. Em Kant, há a afirmação de que a experiência é indispensável, já, em Schwartz, além dessa sua indispensabilidade é ela insubstituível, pois ela é central no uso que cada ser humano faz de si por si em relações sociais de subordinação.

No espaço da saúde se apresenta, concretamente, situações complexas onde é freqüente a combinação entre risco de vida e múltiplas situações de vulnerabilidades. Em virtude dessas diversidades e variabilidades presentes nesse espaço de trabalho, os supervisores de campo nos seus depoimentos, acentuaram a necessidade de supervisão como sendo algo não-planejado, cuja necessidade se ancora na temporalidade ergológica do estudante-estagiário em processo de formação, na temporalidade vital do doente e na temporalidade mercantil, a do tempo do relógio que marca a vida numa sociedade mercantil capitalista.

Nesse meio novo, repleto de variabilidades, é freqüente que o estudanteestagiário, no momento de gerir a sua atividade explicite suas dúvidas e o faça com o intuito de revelar as incertezas diante das bifurcações que se abrem diante das múltiplas convocações do meio e frente à necessidade imperativa de decidir-se por um caminho a seguir. Ensino e assistência se realizam em tensão com o ritmo da atividade do trabalho, tanto no que tange a quantidade e quanto em relação às múltiplas necessidades do trabalho, dando-se em presença das dúvidas dos estudantes-estagiários. 
Essas inculturas parciais interferem no processo do cuidado e requerem que o supervisor de campo esteja atento para aproveitar o momento oportuno, o conhecimento da arte do kairós $^{7}$ (TREDE,1992) para fornecer subsídios conceituais e saberes ergológicos ancorados na experiência própria, nascida do trabalho real. O uso dos saberes é indispensável na realização de microescolhas que envolvam doentes, familiares, equipe de saúde e rede de serviços sócio-assistenciais locais ou regionais.

A atividade de linguagem, na supervisão de estudantes-estagiários, intenta criar pontes para que o supervisor possa pensar sobre os problemas trazidos pelo estudanteestagiário e, em outros momentos, requer encetar diálogo com o estudante-estagiário à medida que isso contribua para que ambos constituam seus próprios "pontos de vista" sobre a situação em questão. Esse movimento entre o falar sobre o[s] problema[s] dos usuário[s] ou do hospital e o falar com o estudante-estagiário se mescla com os momentos em que a situação requer que fale ao estudante-estagiário de um modo mais técnico, ancorado em normas diversas, discutindo diversas concepções de trabalho e de assistência, descortinando outros modos de pensar a atividade em processo de realização e as decisões e microdecisões das quais participará.

No início eu fazia as entrevistas. Depois eu fazia e ela observava. Depois fazíamos em conjunto. Aí, ela fazia e eu observava, e hoje ela faz sozinha.

Depoimento da $9^{\mathrm{a}}$ supervisora de estágio - área ambulatorial

O processo de ensino e de transmissão de saberes não se realiza marcado somente pela linguagem, dá-se também através da efetivação do atendimento na presença do estudante, numa relação face a face. Isso ocorre porque o patrimônio de saberes do Serviço Social não se limita a um corpus de saber delimitado e circunscrito,

\footnotetext{
${ }^{7}$ Trédé afirma que "O kairós aparece então como o ponto de junção dialético de duas durações: a longa maturação do passado e o aparecimento da crise que exige rapidez, a acuidade de um golpe de vista voltado para o futuro [...] Porque o kairós é fugidio, imprevisível, irreversível”. Cf. TRÉDÉ, 1992, p. 19. Revista Serviço Social \& Saúde. UNICAMP Campinas, v. VII-VIII, n. 7-8, Dez. 2009
} 
ele inclui também aspectos de natureza relacional. Martinelli afirma que se torna “imperioso reconhecer que o Serviço Social contemporâneo transita pelos meandros do público, do privado e do íntimo" (2002, p. 6). O supervisor diariamente é desafiado a transmitir os seus saberes para o estudante-estagiário, ou seja, dele é demandado ensinar o seu ofício.

No dia a dia você tentou passar para ela [estudante-estagiária] tudo aquilo que ela precisou aprender que era como lidar com família, paciente, com equipe de trabalho, com outras, com outros profissionais de outras regiões, de outras cidades, e com outros profissionais dentro do hospital que a gente acaba lidando.

Depoimento da $7^{\text {a }}$ Supervisora de Estágio - Área Ambulatorial destaques nossos

No depoimento anterior, no uso da expressão "você tentou" há uma alusão ao fato de não ser possível ter certeza de que foi feita um[a] passa[r]gem de saberes em direção do "sujeito" que ensina para aquele que aprende. Essa incerteza de como fazer para que um quantum de saberes possa transitar entre "sujeitos" já constitui uma característica essencial presente na atividade do transmitir humano. Schwartz marca a especificidade do ato de "transmitir" em situações humanas, uma vez que no transmitir mecânico, o fenômeno da transmissão implica movimento (SCHWARTZ, 2005, p. 230), assim, para analisar o fenômeno do transmitir mecânico procedemos a uma comparação entre o estado inicial e o estado ulterior. Se constatarmos que esse quantum está “integralmente conservado, poder-se-á dizer: [que] "não está acontecendo nada ali"” (ibid, p. 232). No transmitir em situações humanas, esse ato aparece como que “orientado", ou seja, nele há uma "flecha do tempo", que conduz não a um "declínio da diversidade inicial, mas sim a um aperfeiçoamento contínuo desta" (ibid, 233). Essa diferença se dá, segundo Schwartz, porque se "opera essa surpreendente dinâmica de 
conservação-aperfeiçoamento, sempre à espreita, esperando uma minúscula oportunidade para ampliar no ser vivo as normas de vida" (ibid, p. 233).

Uma análise atenta para o depoimento da supervisora nos revela que a ela é pedido [re]convocar um conjunto de saberes híbridos nascidos tanto no corpus de saberes da profissão, quanto os oriundos do direito, do conhecimento de terapêutica, da biologia, do direito social, bem como, as próprias normas antecedentes de natureza diversa que se fazem presente nesse espaço de trabalho, de formação e de assistência à população usuária da saúde. Essa travessia dá-se ancorada em normas antecedentes de natureza diversas, contudo, esse percurso é realizado sem perder de vista a necessidade de realizar uma intervenção pertinente e oportuna que o usuário requer e que a instituição demanda. No decorrer do processo de formação o estudante-estagiário, gradativamente, vai aprendendo a lidar com as múltiplas formas de vulnerabilidades sociais, bem como, com o sistema de proteção social disponível ou não, para dar suporte às necessidades humanas presentes nesse meio de trabalho, intimamente marcado pelo “objeto" vida e morte (JOAZEIRO, 2002, 2008).

$\mathrm{Na}$ abordagem ergológica se afirma que, em toda atividade humana, está presente uma dupla antecipação. A primeira antecipação é a própria atividade de conceituação; trata-se do saber conceitual, da antecipação que se dá antes mesmo que cada um tenha encontrado o ambiente no qual realizará sua atividade (SCHWARTZ, 2000, p. 47 et seq.). A segunda antecipação é aquela que se dá no encontro do protagonista com a atividade a ser realizada, o que requer, do "sujeito", realizar renormalizações e ressingularizações da norma antecedente no aqui e agora da atividade. Esse encontro é imprescritível, nele está presente a relação entre o "sujeito", o conceito e a vida. Essa relação é sempre singular, pois cada um "antecipa o outro, em seu próprio esforço, para tornar inteligível um meio de vida ou de trabalho" (IDEM, 
2006, p. 2). Como afirma Durrive, "o homem tenta imaginar uma tarefa para antecipar a história que ele vai viver, mas a história lhe reserva sempre surpresas e o interpela".

Eu acho que, às vezes, eu fujo muito destas coisas mais técnicas, sabe? Às vezes, até termos técnicos, porque eu estou muito próxima da pessoa.

Depoimento da $11^{\text {a }}$ Supervisora de Estágio

Apreende-se deste depoimento que existe uma diferença substancial marcada pela facilidade que a supervisora sente em "si mesma" ao realizar a sua atividade de assistência direta aos usuários do hospital, onde utiliza uma linguagem que ela denomina de "menos-técnica" com vista a estabelecer uma relação empática na assistência e tornar-se mais "próxima da pessoa", ou seja, do usuário. Ela alude ao diálogo que estabelece com o usuário e sua família, que tem o uso da linguagem como um instrumento privilegiado de encontro com os outros, mas também de comunicação e de transmissão de saberes. A palavra se constituiu numa ferramenta, indispensável no espaço de trabalho do hospital, posto que o "ofício" do assistente social tem uma importante dimensão relacional na qual a atividade de linguagem empreende uma aproximação do OUTRO. Como afirma Freire, para que haja diálogo é preciso ser capaz de "falar com" ao invés de "falar aos outros, de cima para baixo" (1999, p. 127). Essa preocupação de a atividade de linguagem ser utilizada como instrumento de aproximação e não de distanciamento do usuário evidencia o uso particular da palavra como ponte entre "sujeitos".

Assinala, na sequiência, a dificuldade que enfrentou ao realizar a atividade de supervisionar estudantes-estagiários, uma vez que neste campo, a linguagem requer outro uso da palavra, o da atividade de conceitualizar a partir da experiência na relação entre a primeira e a segunda antecipação. Sendo assim, do supervisor é requerido tanto ser capaz de falar com a pessoa e empreender as [re]normalizações indispensáveis para Revista Serviço Social \& Saúde. UNICAMP Campinas, v. VII-VIII, n. 7-8, Dez. 2009 
gerir a própria atividade de trabalho numa relação com as normas diversas, como também, será demandado, saber falar sobre a assistência ao usuário, pois nelas estão presentes as duas antecipações. Diferentemente dessa aproximação pelo uso da linguagem empreendida pela supervisora no atendimento à população usuária, a atividade de supervisionar requer, por parte da supervisora, uma distância do processo de assistência direta ao usuário. Isso lhe exige que tenha como foco a preocupação em contribuir no processo de constituição de um "ponto de vista" do estudante-estagiário, fundado tanto nas particularidades do corpus de saberes da profissão, nas normas, como, sobretudo, na própria experiência no trabalho de supervisão e na realização da assistência a usuários e famílias.

O supervisor para empreender esse percurso utilizará, acima de tudo, da sua palavra $^{8}$, ou seja, da atividade de linguagem ancorada no corpus de saberes da profissão, da saúde, da política pública bem como dos saberes ergológicos, aqueles nascidos dos diversos saberes amealhados no decorrer da sua experiência no trabalho de atender usuários e famílias, bem como dos saberes nascidos da atividade de supervisão.

\section{A GUISA DE CONCLUSÕES}

$\mathrm{O}$ ato de transmitir humano apresenta-se como uma verdadeira dificuldade para o supervisor de campo em virtude de ele requerer tanto a gestão dos saberes ergológicos oriundos da própria atividade concreta de trabalho, que são amealhados no exercício $\boldsymbol{d a}$ profissão, na situação real de trabalho, quanto a gestão de saberes epistêmicos específicos à sua formação os quais são [re]questionados pelos saberes ergológicos nesse exercício, $\boldsymbol{n a}$ atividade concreta de trabalho. Uma dupla gestão aqui

\footnotetext{
${ }^{8}$ Inspiramos-nos em Rosa para empreender essa análise. Cf. RosA, M. I, 2004, p. 152.

Revista Serviço Social \& Saúde. UNICAMP Campinas, v. VII-VIII, n. 7-8, Dez. 2009
} 
tem lugar, a qual explicita a [re]convocação de ambos os saberes, um interpenetrando no outro, na transmissão da orientação ao estudante-estagiário.

A relação assistencial e a de supervisão requerem de quem as realiza que empreenda uma combinação entre três tempos, o do ontem - que se constitui nos saberes que se ancoram nos aspectos da historicidade de um campo de saber e de um meio de trabalho; o do aqui e agora - indispensável na intervenção que requer sempre compreender e decifrar o instante; e o tempo do devir - do amanhã. Os dois primeiros tempos têm uma íntima relação com o tempo do amanhã, à medida que neles se busca realizar escolhas que tem implicações sobre o devir. Na perspectiva da temporalidade do devir, as ações do presente buscam prescrever formas de ação no aqui e agora que impactem no amanhã. Contudo, seus resultados são, em tendência, incertos, já que o movimento que eles imprimem depende da qualidade sinérgica dos coletivos que podem ser capazes ou não de colocar em movimento formas pertinentes de atenção ao usuário. Essas formas de intervenção se ancoram em normas diversas e precisam ser ressingularizadas, a partir das particularidades presentes em cada situação.

No espaço da supervisão no campo de estágio se dá um encontro invisível entre os saberes epistêmicos e ergológicos na atividade de orientação do estudante-estagiário, nele o supervisor precisará estar atento para compreender o momento que vive o estudante-estagiário no sentido de ser capaz de decifrar suas necessidades. É da contínua realização desse duplo processo que advêm as "sínteses provisórias", contudo indispensáveis para ancorar a assistência, aqui considerada no sentido de intervir "na vida dos outros" (SCHWARTZ, 2007, p. 15). A intervenção tem implicações tanto na vida do usuário, quanto no ensino do estudante-estagiário em formação, quanto no aprendizado do próprio assistente social supervisor. Essa atividade convoca o supervisor a colocar em palavras esses ínfimos e microscópicos debates de normas que 
conferem a essa atividade um triplo sentido, ao mesmo tempo, de caráter pedagógico, epistemológico e político.

\begin{abstract}
This article discusses the conjuncture between experience and knowledge that happens in the working activity of internship supervision of and in Social Work supervised training at Public Teaching Hospital. We tried to understand and explain the independent and indissociable character of the knowledge always present in the supervisor working, which is materialized in the dialogue constructed in the presence of the corpus of the knowledge ressulting from the profession and the one coming from others fields of knowledge (pole 1); of the knowledge from the ergological discipline, present in the conjuncture with the user population, with the life risk and with the work itself (pole 2); these poles are in the presence of and tensioned with mercantile values, the values of common well-being and of life (pole 3) which mark, in an ineluctable way, such a milieu of working and formation. It has been used the categories and conceptual tools of the ergological approach, - Relatively Pertinent Collective Entity (ECRP) [Entidade Coletiva Relativamente Pertinente], corpo-si, always a drama of one's use of oneself, industrious human competence - to explain that this work activity of and in training is, through the same action, the use by itself and the use of itself by somebody else (SCHWARTZ, 2000). We also emphasize the necessity of being up for discussion the already established conception of training as "field of training", in view of judging it as the heiress of another logic: the one of the work as an act of execution.
\end{abstract}

KEYWORDS: Ergological Approach, Internship Supervision, Social Work, Public Health 


\section{REFERÊNCIAS BIBLIOGRÁFICAS}

ABESS/CEEPSS. Diretrizes Gerais para o Curso de Serviço Social. Com base no currículo mínimo aprovado em Assembléia Geral Extraordinária de 08 de novembro de 1996. Cadernos ABESS, São Paulo, v. 7, p. 58-76, nov. 1997.

BARRERA, J. F. La Supervisión en el trabajo social. Barcelona, Buenos Aires México: 1997. 208 p. (Paidós Trabajo Social 4)

BURIOLLA, M. A. F. Supervisão em Serviço Social: o supervisor, sua relação e seus papéis. 2. ed. São Paulo: Cortez, 1996. 209 p.

O Estágio Supervisionado. São Paulo: Cortez, 1999. 176 p.

CAnguilhem, G. O Normal e o Patológico. 4. ed. Rio de Janeiro: Forense Universitária, 1995. 307 p.

DURAFFOURG, J. Um robô, o trabalho e os queijos: algumas reflexões sobre o ponto de vista do trabalho. In: DIEESE (org.). Emprego e Desenvolvimento Tecnológico: Brasil e contexto internacional. São Paulo: CNPq, FAT, SEFOR/Mtb, 1998. p. 123-44.

DURRIVE, L. Formação, trabalho, juventude: uma abordagem ergológica. ProPosições, v. 13, n.3 (39), p. 19-30, set./dez. 2002.

ELIAS, N. A sociedade dos indivíduos. Rio de Janeiro: Jorge Zahar, 1994. 201 p.

FREIRE, P. Pedagogia da autonomia: saberes necessários à prática educativa. 11 ed., São Paulo: Paz e Terra, 1999, 165 p. (Coleção Leitura)

JOAZEIRO, E.M.G. Estágio Supervisionado: experiência e conhecimento. Santo André, SP: ESETec, 2002. 171 p.

, Supervisão de Estágio: formação, saberes, temporalidades. Santo André, SP:

ESETec, 2008, 260 p.

KANT, E. Deuxième Partie. Logique transcendantale. In: Critique de la raison pure. Paris: PUF, 2004, p. 76-84. 
MAGGI, B. Les conceptions de la formation et de l'éducation. In: (Org.)

Manières de penser, manières d'agir en éducation et en formation. Paris: PUF, 2000. p. 1-32.

ROBINSON, V. Supervision in Social Case Work. Chapel Hill: University of North Caroline, 1936.

ROSA, M. I. Trabalho - nova modalidade de uso de si: debates e confronto de valores. Pro-Posições. Campinas, v. 11, n. 2 (32): 51-60, jul. 2000.

Usos de si e testemunhos de trabalhadores: Com estudo crítico da Sociologia Industrial e da Reestruturação Produtiva, São Paulo: Letra \& Letras, 2004.

ROSA, M. I. et al. Trabalho, não-trabalho, trabalhadores: construindo um projeto coletivo de histórias oral. In: SEMINÁRIO DE HISTÓRIA ORAL NO SUDESTE: AVALIAÇÃO E PERSPECTIVA. USP. São Paulo, 30 a 31 de março de 1998. Mimeografado.

SCHWARTZ, Y. Spécificités du travail. In: Expérience et connaissance du travail. Paris: Éditions Sociales, 1988, p. 471-94.

.Introduction. Métier et Philosophie. In: Le paradigme ergologique ou un métier de Philosophe. Toulouse: Octares, 2000, p. 7-68.

Disciplina epistêmica, disciplina ergológica. Paideia e politeia. Pro-Posições, Campinas, SP, v. 13, n. 1 (37), p. 126-49, jan./abr. 2002.

Transmissão e Ensino: do mecânico ao pedagógico. Pro-Posições, v. 16, n. 3 (48), p. 229-44, set./dez. 2005.

Do «desvio teórico» à «atividade» como potência de convocação dos saberes.

Serviço Social \& Saúde, Campinas, SP, ano VI, n. 6, p. 1-19, maio 2007. 
TREDE, M. Introduction. In: Kairós L’à-propos et l'occasion: (le mot et la notion, d'Homère à la fin du IV ${ }^{\mathrm{e}}$ Siècle avant J.C). Paris: Éditions Klincksieck: 1992, p. 15-21. (Études et Commentaires, 103)

VIEIRA, B. O. Supervisão em Serviço Social. Rio de Janeiro: Agir Editora, 1974, 326 p. 
